\title{
3-D gravity modeling of basement reliefs an offshore case study in the Persian gulf, Iran
}

\author{
Ata Eshaghzadeh ${ }^{1 *}$, Mahfam Parto $^{2}$, Zohreh Moeini Hekmat $^{2}$ \\ ${ }^{1}$ Graduate student of geophysics, Institute of Geophysics, University of Tehran, Iran \\ ${ }^{2}$ Graduate student of geophysics, Islamic Azad University, Iran \\ *Corresponding author E-mail: eshagh@ut.ac.ir
}

Copyright $\odot 2014$ Eshaghzadeh et al. This is an open access article distributed under the Creative Commons Attribution License, which permits unrestricted use, distribution, and reproduction in any medium, provided the original work is properly cited.

\begin{abstract}
In this paper we have proposed a three-dimensional approach to determine depth of basement in which the density contrast varies parabolically with depth. This program based on Newton's forward difference formula that with optimization of gravity anomalies calculate depths of basement reliefs indeed are anticlinal and synclinal structures has been buried under sediments. This structures are the causes of the positive and negative gravity anomalies. We assume the measured gravity fields have been distributed on a horizontal plane and also sedimentary basin is combined of juxtaposition 3-D cubic prisms. The measurement stations of the gravity field (grid nodes) coincide with center blocks. The initial depth is computed using gravity data and the estimated depths are adjusted with iteration. The advantage of the method is utilization of positive and negative gravity anomalies together as two inputs for written algorithm as well as application of a coded non-linear filter. The efficiency of the code is illustrated with a set of synthetic gravity anomalies. Further, the code is exemplified with the gravity anomalies of an offshore case study in the Persian Gulf, Iran. The purpose of exploratory project in this area will include the development of Hydrocarbon Fields.
\end{abstract}

Keywords: Basement, Gravity Anomalies, Newton's Forward Difference Formula, Non-Linear Filter, Persian Gulf.

\section{Introduction}

Folded structures such as anticlines and synclines are among the most important geological structures as hydrocarbon traps in gravimetric exploration targets. In many geophysical research projects these structurs that found basement reliefs has been covered with thick sediments. The positive and negative observed residual gravity anomalies in these regions are the results of ascent and descend basement due to tectonic activities, respectively.

Already various methods were proposed for modeling of sedimentary basins as the density of sediments and sedimentary rocks varies with depth [1], [2], [3], [4], [5].

In this paper is used of the Chakravarthi's inversion method [6] for 3-D gravity modeling the basement reliefs an offshore probable hydrocarbon field in the Persian Gulf region, Iran. Chakravarthi's method [6] has been defined just for the negative gravity anomaly. Much of the exploratory fields contain the positive and negative gravity anomalies. We are provided both anomalies for gravity modeling. For estimation the depth, sedimentary basin is adapted with arbitrary geometry. In this paper the subsurface is defined using a large number of 3-D prisms (Fig. 1A) with the computed initial depths of the observated gravity data. The depths will improve with increasing iteration.The density contrast between the top of sediments and the basement increase parabolically with depth [7].

The program code is written in the matlab software which enables to obtain depth estimates of a sedimentary basin and naturally bedrock morphology from the measured gravity fields. Using nonlinear filters was proposed by Naudy and Dreyer [8] to remove noise from magnetic profiles. We with inspiration of the Naudy's method for getting a smooth deep map of actual gravity data, developed a matlab code until eliminate the short wavelength automatically. The applicability and competency of the code is illustrated on a synthetic model. 


\section{Methodology}

The parabolic density function (PDF) is defined as [7]

$\Delta \rho(z)=\frac{\Delta \rho_{0}^{3}}{\left(\Delta \rho_{0}-\alpha z\right)^{2}}$

Here $\Delta \rho(\mathrm{z})\left[\mathrm{gr} / \mathrm{cm}^{3}\right]$ is the density contrast at a given depth $\mathrm{z}[\mathrm{Km}], \Delta \rho_{0}$ is the density contrast observed at the ground surface and $\alpha$ is a constant. The sign of $\Delta \rho(\mathrm{z})$ and $\alpha$ for negative residual gravity anomaly is negative and positive respectively. The sign of the variables for positive residual gravity anomaly is contrary. The gravity response of sedimentary basin at any grid node (i, j) of a rectangular mesh (Fig. 1B) is given [9] as

$g_{\text {sba } \sin }(i, j, 0)=\sum_{k=2}^{N O Y}-1 N O X-1, g_{\text {PRISM }} k, l$,

Where NOX and NOY are the number of grid points along X- and Y-axes of the Cartesian coordinate system.

Chakravarthi (2004) presented an equation for compute gravity response of a 3-D prism (Fig. 1C). The mesh covers a sedimentary basin completely. The problem of interpretation is to solve (NOY-2) $\times(\mathrm{NOX}-2)$ depth estimates from NOY $\times$ NOX observations. The method of interpretation begins by calculating the initial depth estimates of a sedimentary basin as [6]

$z(m, n)=\frac{g_{o b s}(m, n) \Delta \rho_{0}}{41.89 \Delta \rho_{0}^{2}+\alpha g_{o b s}(m, n)}$

$\mathrm{m}=2$, NOY -1 and $\mathrm{n}=2$, NOX- 1 with with $\mathrm{z}(\mathrm{m}, \mathrm{n})=0$, for $\mathrm{m}=1$ and NOY and $\mathrm{n}=1$ and NOX.

Using approximate initial depth estimates at any points, calculated gravity of a sedimentary basin compute using equation Chakravarthi 2004 [6]. In each iteration, the differences between the observated and calculated gravity is used to improve the depth estimates of the 3-D blocks following the Newton's forward difference approximation [6]

$z_{k+1}(m, n)=z_{k}(m, n)+\frac{g_{o b s}(m, n)-g_{s b a \sin }(m, n)}{2 \pi G \Delta \rho(z)}$

$\mathrm{m}=2, \mathrm{NOY}-1$ and $\mathrm{n}=2, \mathrm{NOX}-1 . \mathrm{G}$ is the universal gravitational constant. Here $\mathrm{k}$ shows the number of iterations.

The surface density contrast $\left(\Delta \rho_{0}\right)$ expressed in $\mathrm{g} / \mathrm{cm} 3$, constant of parabolic density function $(\alpha)$ expressed in $\mathrm{gr} / \mathrm{cm} 3 / \mathrm{km}$, grid node spacing, distances and depth ( $\mathrm{z}$ ) expressed in $\mathrm{km}$ and gravity anomaly $(\mathrm{g})$ expressed in mgal.

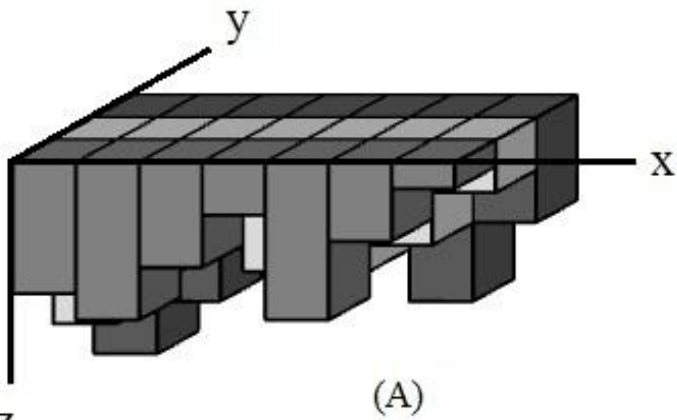

Z

(A)

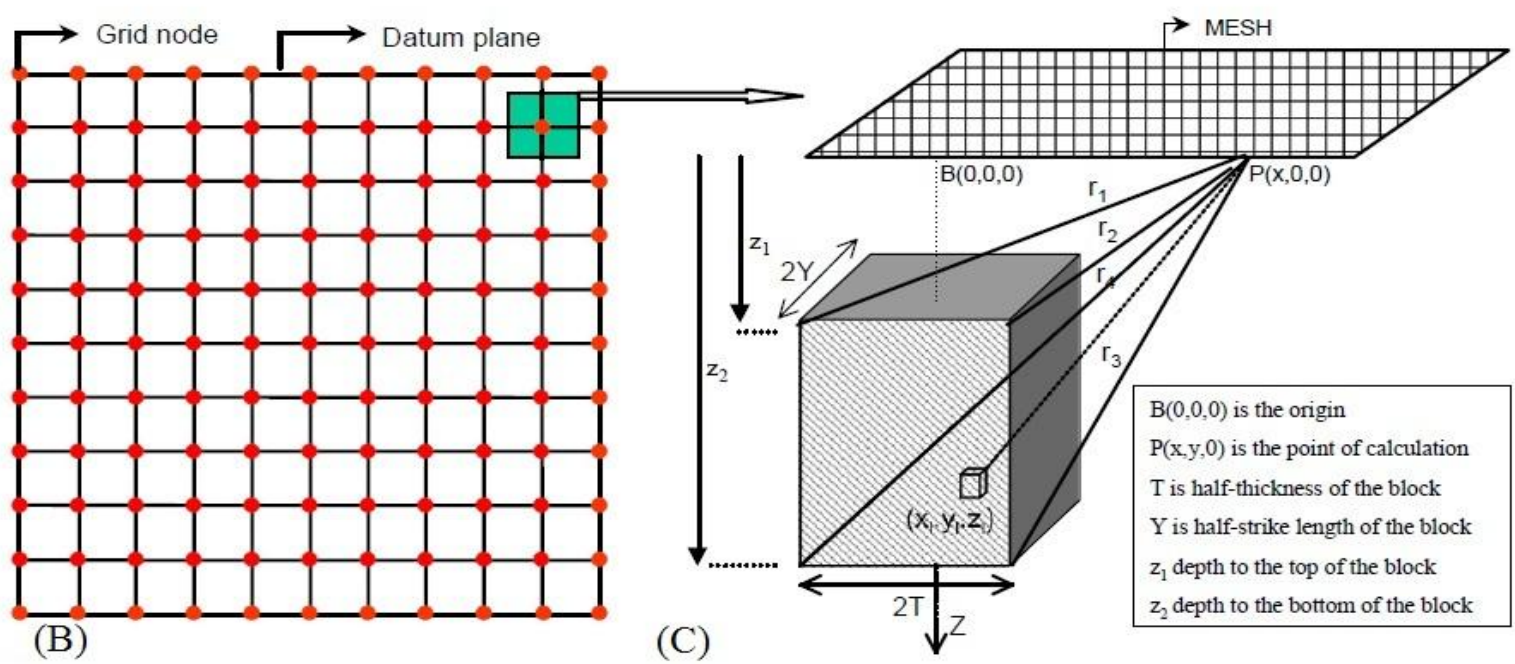

Fig. 1: (A) 3d Model of Sedimentary Basin Formed of Vertical Prisms; (B) Geometry of A Rectangular Mesh with Top View of A 3-D Building Block; (C) Geometry of 3-D Building Block. B and C are Adoptive from Chakravarthi 2004. 


\section{Synthetic model}

The synthetic model include of 81 grid nodes with $9 * 9$ computational points at an interval of $2 \mathrm{~km}$ along the $\mathrm{X}$-axis and $2 \mathrm{~km}$ along the $\mathrm{Y}$-axis. The plan and 3-D view of the synthetic model of a basin with $3.6 \mathrm{~km}$ as maximum depth and 0.1 $\mathrm{km}$ as minimum depth from surface are shown in Fig. 2A and B, respectively.
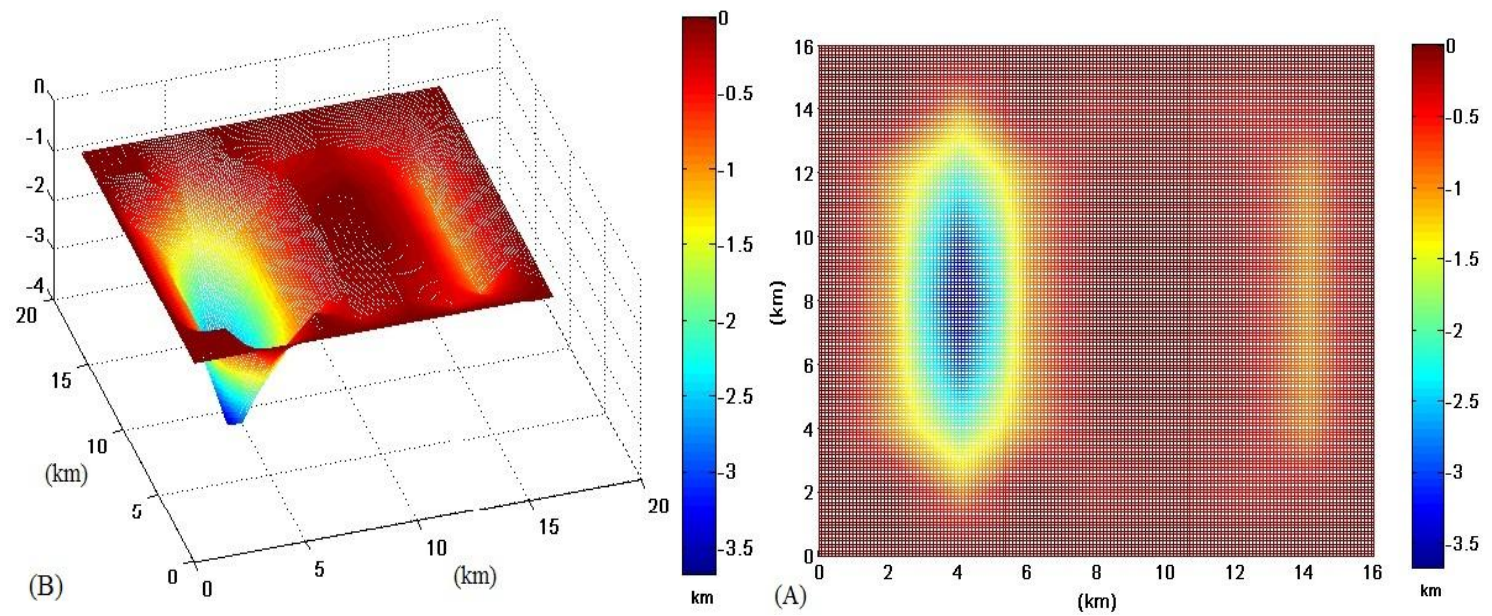

Fig. 2: Plan (A) and 3D View (B) of a Synthetic Deep Model

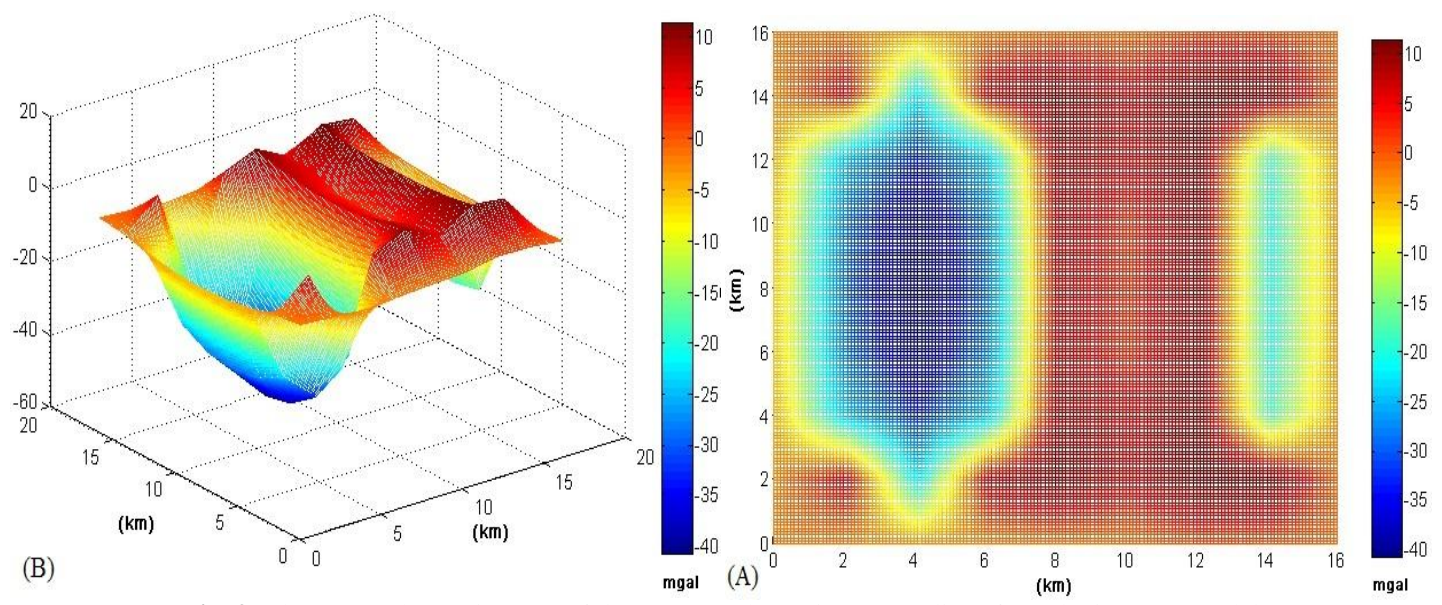

Fig. 3: Plan (A) and 3D View (B) of the Computed Gravity Anomalies of Synthetic Deep Model

The calculated gravity field of the model with assumption the values of $\Delta \rho_{0}=-0.7 \mathrm{gr} / \mathrm{cm} 3$ and $\alpha=0.02 \mathrm{gr} / \mathrm{cm} 3 / \mathrm{km}$ for the depths equal or more than one $\mathrm{km}($ depth $<=-1)$ and $\Delta \rho_{0}=0.7 \mathrm{gr} / \mathrm{cm} 3$ and $\alpha=-0.02 \mathrm{gr} / \mathrm{cm} 3 / \mathrm{km}$ for the depths under one $\mathrm{km}$ (depth $>-1$ ) is shown in Fig. 3.

The computed gravity anomalies using the described inversion method is shown in Fig. 4. The inversion has resulted $3.6 \mathrm{~km}$ as maximum depth and $0.1 \mathrm{~km}$ as minimum depth to the basement. The estimated depths comform the depths of synthetic model, thereby verifying the validity of the method (Fig. 5).

\section{Field example}

The Persian Gulf Basin is the richest region of the World in terms of hydrocarbon resources. Stable subsidence and the unique landscape-climatic conditions favored the accumulation of a very thick sedimentary lens of carbonate rocks and evaporites (up to $12-13 \mathrm{~km}$ and more). Carbonate rocks with excellent reservoir properties are widespread, while the evaporites play the role of regional fluid seals [10]. The case study region situate between longitude $52^{\circ} 6^{\prime}$ to $54^{\circ} 57^{\prime}$ and latitude $25^{\circ} 40^{\prime}$ to $27^{\circ} 22^{\prime}$ (Fig. 6). This zone is bounded by the following UTM coordinates in WGS-84 UTM zone 39N (table 1). 

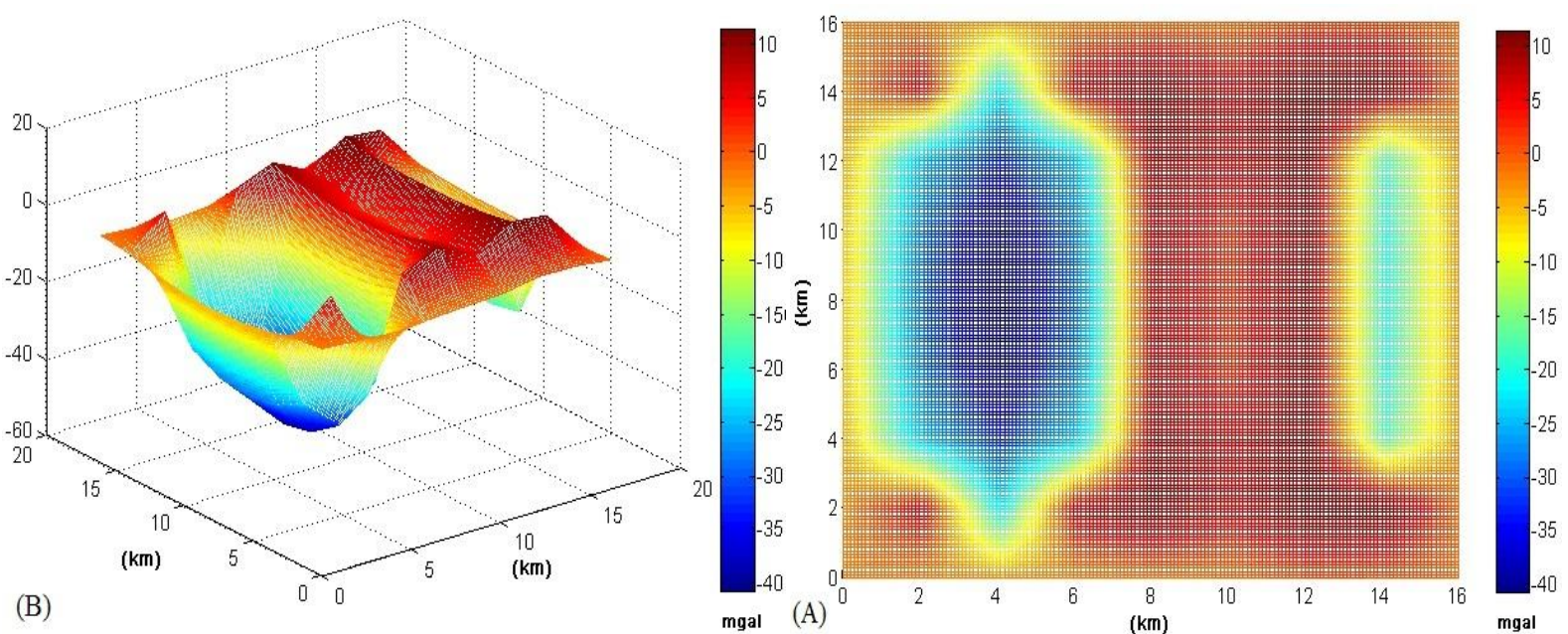

Fig. 4: Plan (A) and 3-D (B) View of the Inverted Gravity Anomalies
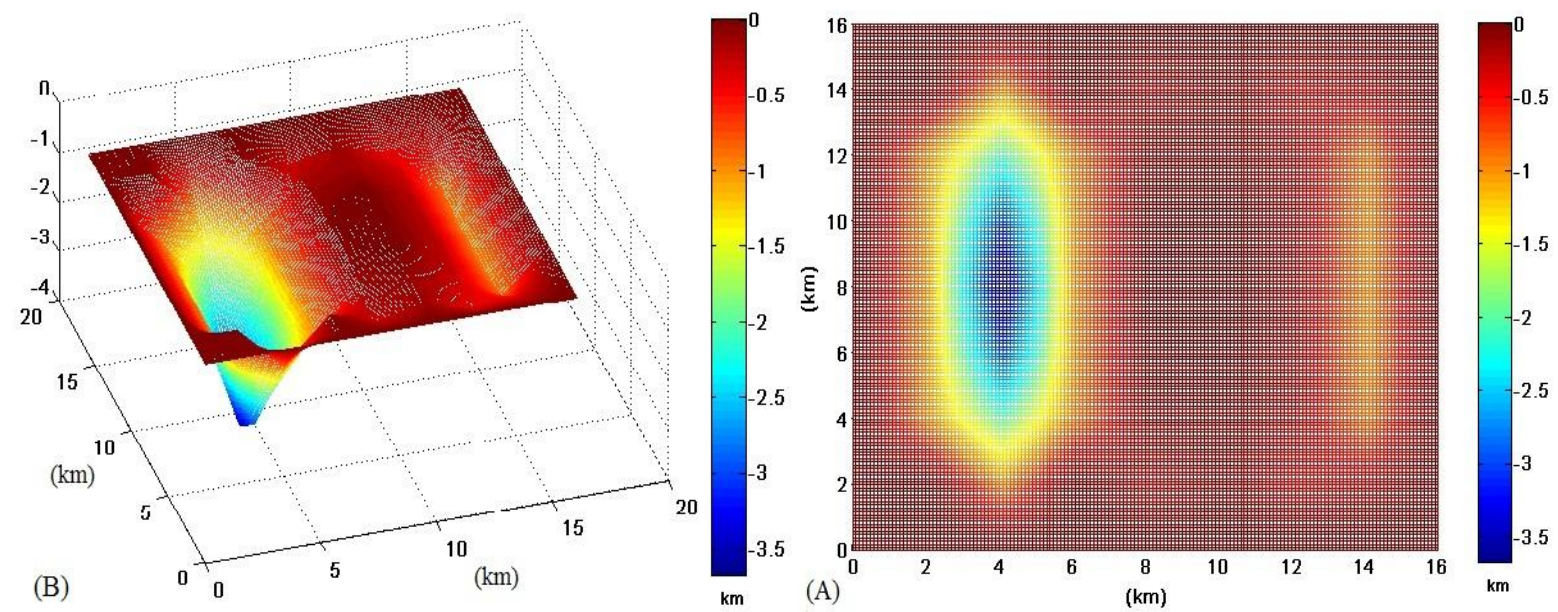

Fig. 5: Plan (A) and 3D View (B) of the Inverted Depths

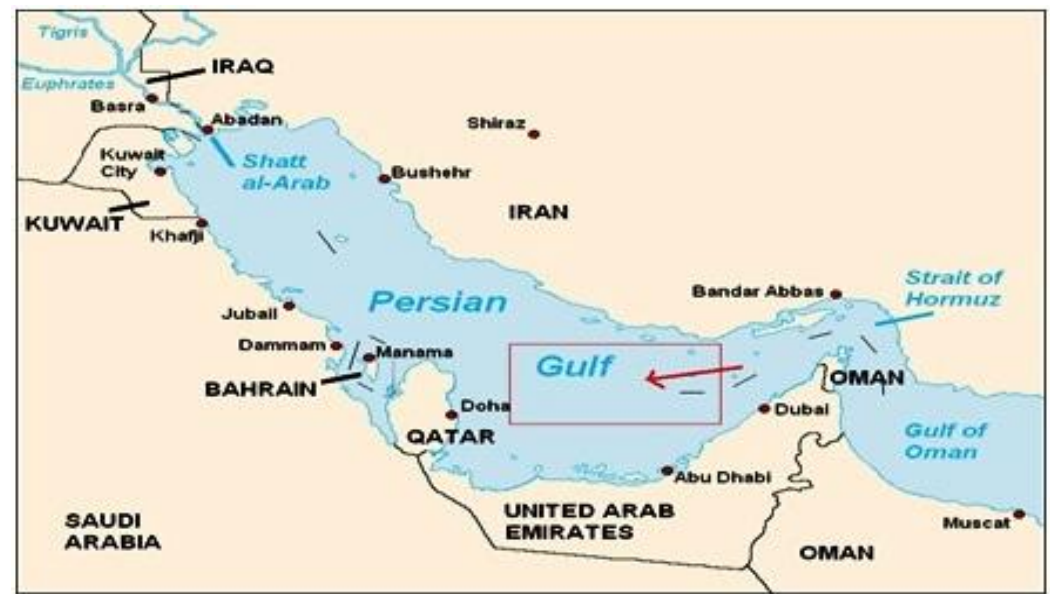

Fig. 6: The Red Rectangular Show the Location of the Exploratory Region

Table 1: UTM Coordinates of the Exploratory Region in WGS-84 UTM Zone 39N

\begin{tabular}{ccc}
\hline Corner & UTM X $(\mathrm{m})$ & UTM Y $(\mathrm{m})$ \\
\hline 1 & 610000 & 2840000 \\
2 & 610000 & 3070000 \\
3 & 900000 & 2840000 \\
4 & 900000 & 3070000 \\
\hline
\end{tabular}

After the correction of the measured marine gravity data, was drawn the complete bouguer gravity anomaly map (Fig. 7). Fig. 8 shows the residual gravity anomaly that includes the positive and negative anomalies. 


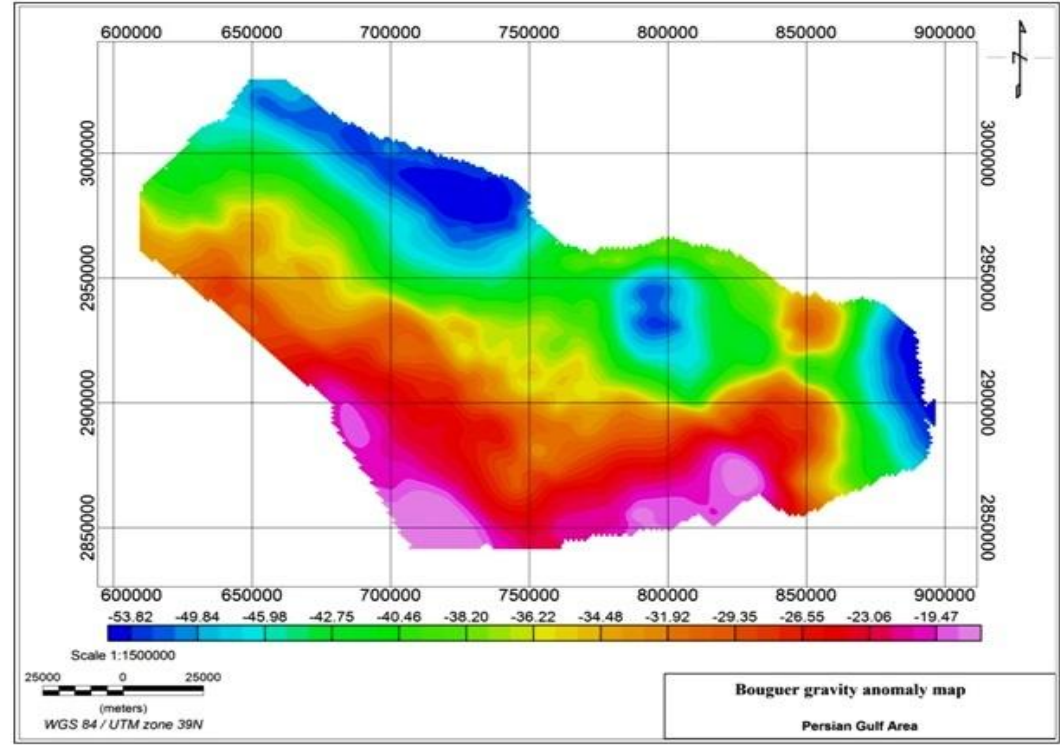

Fig. 7: Bouguer Gravity Anomaly Map of the Exploratory Region in the Persian Gulf

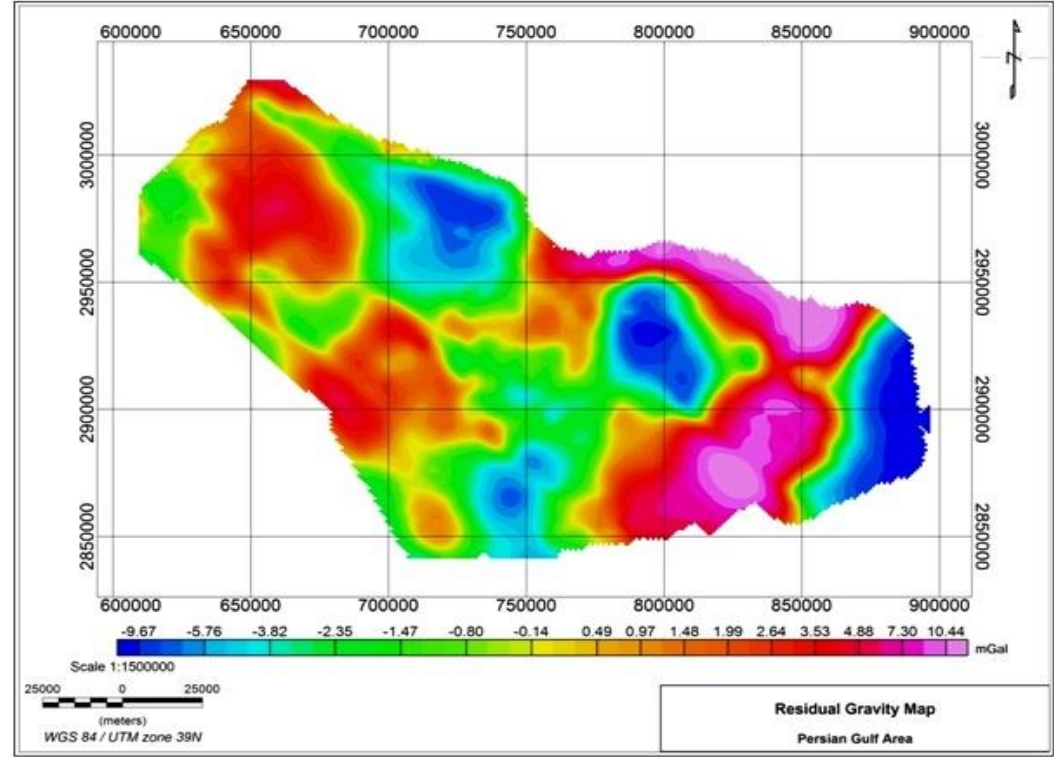

Fig. 8: Residual Gravity Anomaly Map of the Exploratory Region in the Persian Gulf

As already explained in this method for bedrock 3D modelling is used of both positive and negative anomalies. Gravity sampling accomplished from the residual gravity anomaly map with an interval $10 \mathrm{~km}$ along the $\mathrm{X}$-axis and $10 \mathrm{~km}$ along the Y-axis in order to obtain 231 grid nodes. Fig. 9 and 10 show the observed and calculated gravity field maps of the sightly region respectively.

Utilization density contrast depth data from available deep borehole and stratigraphy studies we spoted values of $\Delta \rho_{0}=-0.45 \mathrm{gr} / \mathrm{cm} 3$ and $\alpha=0.04 \mathrm{gr} / \mathrm{cm} 3 / \mathrm{km}$ for the negative anomalies and values of $\Delta \rho_{0}=0.45 \mathrm{gr} / \mathrm{cm} 3 \mathrm{and} \alpha=-0.04$ $\mathrm{gr} / \mathrm{cm} 3 / \mathrm{km}$ for the positive anomalies. The plan view, 3-D view of basement relief models of the submarine exploratory region has been shown in Fig. 11. The maximum and minimum thickness of the sediment about $17.6 \mathrm{~km}$ and $1.7 \mathrm{~km}$ was acquired respectively. The interpreted results of the mentioned basin agree well with borehole information.

\section{Conclusion}

Among important aims in the gravimetric studies is determination the limits, depth and formation of the folded structures buried under sediments especially in the hydrocarbon discoveries.

The written computer program, calculate gravity and depth values whereas The density contrast is assumed to be varying parabolically with depth. The output results save in excel files moreover exhibit their plan and 3D form . In places without the gravity data, the code consider zero values for the computed gravity and depth. The computed gravity response and depths of the synthetic model fit truly with the observed gravity response and initial supposed 
depths thereby the validity of the proposed scheme is justified. The interpretation of marine gravity data using described procedure, show very good conformity with the consequences of the other geophysical methods.

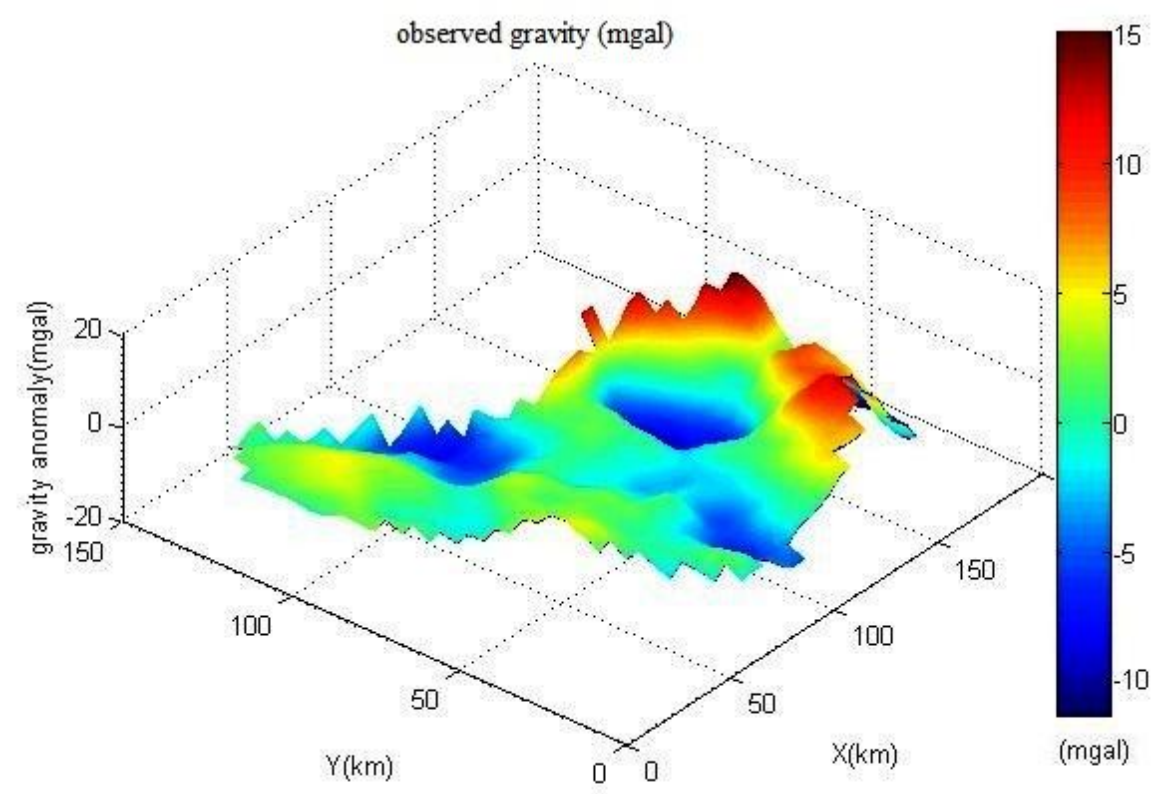

Fig. 9: Observed Gravity Field Map of Under Study Region in the Persian Gulf

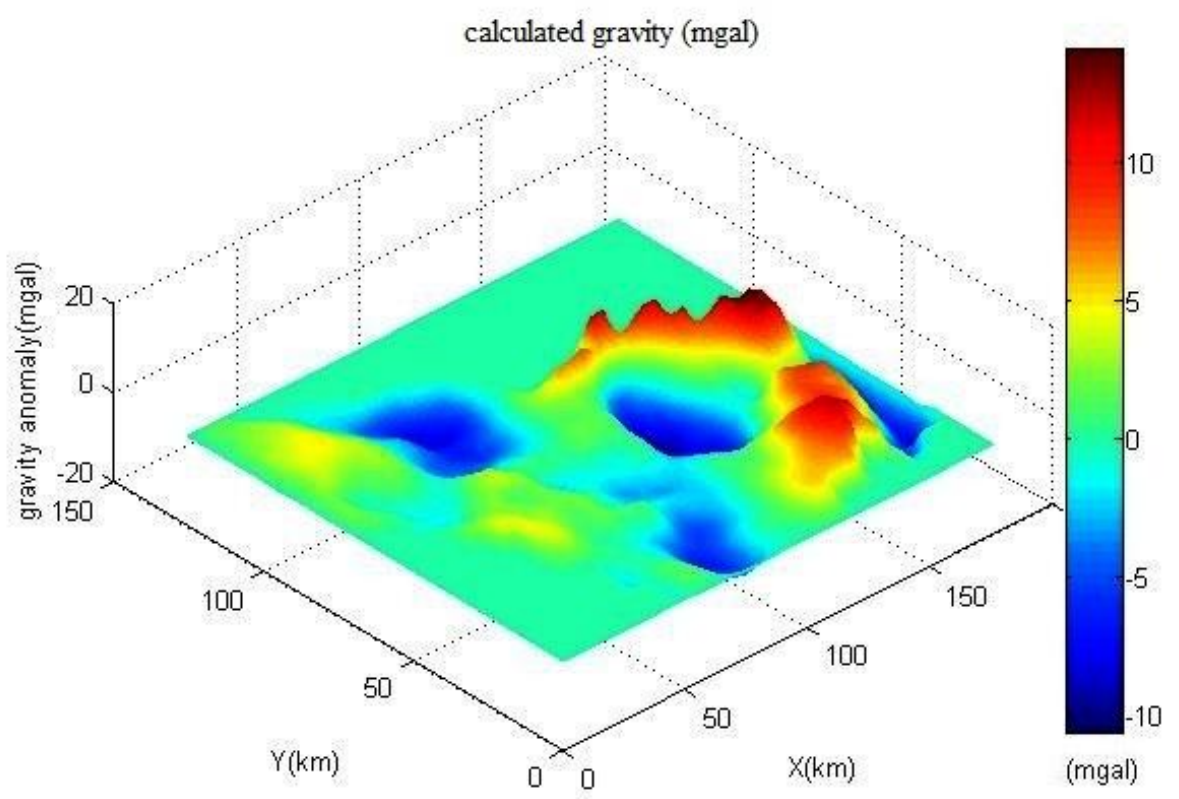

Fig. 10: Calculated Gravity Field Map of Under Study Region in the Persian Gulf 


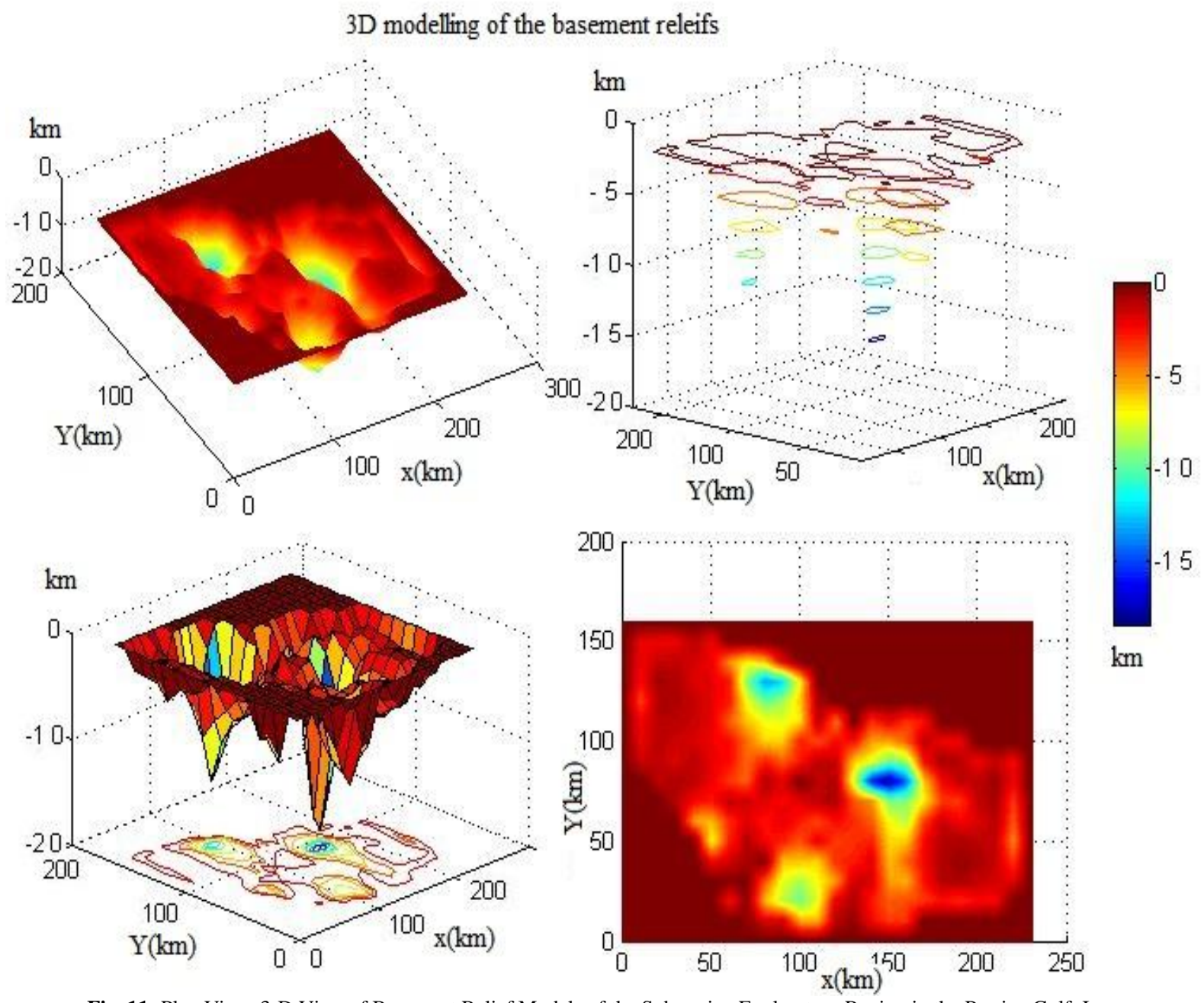

Fig. 11: Plan View, 3-D View of Basement Relief Models of the Submarine Exploratory Region in the Persian Gulf, Iran

\section{References}

[1] Athy, L.F., Density, porosity, andcompact ion of sedimentary rocks. Bulletin of the American Association of Petroleum Geologists 14(1930) $1-24$.

[2] Hedberg, H.D., The effect of gravitational compaction on the structure of sedimentary rocks. American Association of Petroleum Geologists Bulletin 10(1936) 1035-1072.

[3] Weller, J.M., Compaction of sediments. Bulletin of the American Association of Petroleum Geologists 43(1959) 241-287.

[4] Ham, H.H., New charts help estimate formation pressure. Oil Gas Journal 65(1966) 58-63.

[5] Foster, J.B., Whalen, H.E.,Estimation of formation pressures from electrical surveys - offshore Louisiana. Journal of Petroleum Technology 18(1966) 165-171. http://dx.doi.org/10.2118/1200-PA.

[6] Chakravarthi, V., Sundararajan, N., Automatic 3-D gravity modeling of sedimentary basins with density contrast varying parabolically with depth. Computers \& Geosciences 30 (2004) 601-607. http://dx.doi.org/10.1016/j.cageo.2004.03.014.

[7] Chakravarthi, V., Singh, S.B., Ashok Babu, G., INVER2DBASE-A program to compute basement depths of density interfaces above which the density contrast varies with depth. Computers \& Geosciences 27 (2001) 1129-1133. http://dx.doi.org/10.1016/S0098-3004 (01)00035-8.

[8] Naudy, H., Dreyer, Essai de filtrage non-linéaire appliqué aux profils aéromagnétiques.Geophysical Prospecting 16(1968) $171-178$. http://dx.doi.org/10.1111/j.1365-2478.1968.tb01969.x.

[9] Chakravarthi, V., Raghuram, H.M., Singh, S.B., 3-D forward gravity modeling of density interfaces above which the density contrast varies continuously with depth. Computers \& Geosciences 28 (2002), 53-57. http://dx.doi.org/10.1016/S0098-3004 (01)00080-2.

[10] Konyuhov, A. I., Maleki B., The Persian Gulf Basin: Geological history, sedimentary formations, and petroleum potential. Lithology and Mineral Resources, Volume 41(2006) 344-361. http://dx.doi.org/10.1134/S0024490206040055. 